\title{
Impact of Malocclusion on Quality of Life in Sudanese Dental Students
}

\author{
Dr Fatima A Elmahgoub,' Dr Amal H Abuaffan² \\ Dental Surgeon, ${ }^{2}$ Associate Professor, Department of Orthodontics and Pedodontics \\ University of Medical Sciences \& Technology, Khartoum, Sudan
}

Correspondence: Dr Amal Abuaffan Email: amalabuaffan@yahoo.com

\section{ABSTRACT}

Introduction: Both psychological and social factors come to play when analyzing oral health-related quality of life, and recent developments have shown that more focus has been placed on patients' own perceptions of oral health status and oral health care systems to understand their needs, fulfillment with treatment, and ultimately the perceived overall quality of health systems.

Objective: To assess the impact of orthodontic treatment needs on oral health-related quality of life of dental students.

Materials \& Method: A cross-sectional study was done on a random sample of 100 dental students aged 17-23 years at the University of Medical Sciences \& Technology in Sudan. Each subject was assessed for orthodontic treatment need using Dental Health Component (DHC) of Index of Orthodontic Treatment Needs (IOTN). Each subject was given an Oral health-related quality to life questionnaire to complete the Oral Health Impact Profile (OHIP).

Result: The oral health-related quality of life was generally good. Those with 'definite need for treatment' showed higher impact on oral health in relation to functional limitation and physical pain, than those who had 'borderline need', 'little need', or 'no need for treatment'. Males with 'borderline' and 'definite need for treatment' generally showed higher impact on oral health than the female counterpart. However, this was not statistically significant.

Conclusion: Malocclusion does not seem to affect the oral health-related quality of life to a significant degree.

Keywords: malocclusion, oral health impact profile, oral health-related quality of life, orthodontic treatment need

\section{INTRODUCTION}

The quality of life as related to oral health has been defined as: "the absence of negative impacts of oral conditions on social life, and a positive sense of dento-facial selfconfidence". This implies that both psychological and social factors come to play when analyzing oral health-related quality of life.' During the past few decades, orthodontics has become of increasing importance amongst various age groups. ${ }^{2}$ Because of the great interest and high demand for orthodontic treatment, many occlusal indices have been developed to categorize and prioritize treatment. These indices are based on the severity of the malocclusion and the adverse effects it has on oral health. ${ }^{3}$ Orthodontic treatment, however, unlike many other treatment, depends not only on the clinician, but also on the patients' point of view due to its association with social and psychological aspects. ${ }^{4}$ It was found that the decision to have treatment is not just based on the severity of malocclusion, but also on the patient's desire to improve appearance. ${ }^{5}$

Recent studies focus on patients' own perceptions of oral health status and oral health care systems to understand their needs, fulfillment with treatment, and ultimately the perceived overall quality of health. This in turn helps clinicians to understand the importance of patient-centered treatment, which will greatly improve the outcome on both sides.6.7,8 $\mathrm{A}$ systematic review of 23 articles performed by Liua indicated a modest association between malocclusion and the need for orthodontic treatment with quality of life.?

More attention is required in understanding the physical, social, and psychological impact of malocclusion on oral healthrelated quality of life since it provides more understanding of the demand for orthodontic treatment. Consequently the use of 'oral health-related quality of life' is recommended for orthodontists to supplement clinical findings, since its outcome does not essentially correlate with such objective findings. ${ }^{6}$

Most studies of psychosocial aspects of malocclusions have been undertaken in developed countries, where people are more likely to have their basic needs met and orthodontic treatment is partially offered in public health services. However in developing countries; the relationship between malocclusion, esthetic impact, and quality of life is largely unexplored. ${ }^{10}$

The Dental Health Component of Index of Orthodontic Treatment Needs (IOTN-DHC) classifies malocclusion based on 
particular occlusal features which are considered important for dental health. It has five severity levels that records the dental health need for orthodontic treatment. ${ }^{11,12}$

The Oral Health Impact Profile (OHIP) is widely used to measure dental outcomes in terms of the impact on quality of life related to oral health. It was designed to be applied to various oral conditions. The items in the OHIP are assembled into seven domains: functional limitation, physical pain, psychological discomfort, physical disability, psychological disability, social disability, and handicap. ${ }^{13}$ Many previous studies reported a significant association between malocclusion and Oral Health Related Quality of Life (OHRQOL). 3,6,14-16

This study aims to answer following questions: do various orthodontic treatment need related to dental health have an impact on oral health-related quality of life, does gender significantly affect the oral health-related quality of life, and is there a difference of OHIP scores between genders in relation to IOTN-DHC.

\section{MATERIALS AND METHOD}

The cross-sectional study was carried out at the Academy Charity Teaching Hospital (ACTH) - University of Medical Sciences \& Technology (UMST), Faculty of Dentistry, Khartoum during November 2012 to February 2013. Permission and authorization was obtained from UMST. All participants were given a concise explanation about the aim and method of the study, and asked to sign a consent form.

The research included second to fifth year dental students at UMST. The subjects were excluded from the study if the student is having active orthodontic treatment and those who had previous orthodontic treatment.

The sampling technique used was stratified random sampling. The desirable sample size was 100 . The study population was divided into two strata, one consisting of males and other with females. The individuals who have met the inclusion criteria were chosen randomly from a registration sheet.

Once the consent was obtained, each individual was assessed for orthodontic treatment needs using the Dental Health Component of Index of Orthodontic Treatment Need (IOTN$\mathrm{DHC}$ ). Each subject was seated on a dental chair, and an impression using a stock tray and alginate impression material was taken, washed out and disinfected, then casted using plaster. Subsequently, the cast was studied and measured using the MOCDO convention to identify the most severe trait in each individual; where:

$$
\begin{aligned}
& M=\text { Missing teeth } \\
& O=\text { Overjet } \\
& C=\text { Crossbite } \\
& D=\text { Displacement of contact points } \\
& O=\text { Overbite }
\end{aligned}
$$

A grade was given on the basis of the single most severe feature of the malocclusion. In the present study Grade 4 and Grade 5 of $\mathrm{DHC}$ were combined. The index was graded as follows:

Grade 1: No treatment need

Grade 2: Minimal/little treatment need

Grade 3: Moderate/borderline treatment need

Grade 4 \& 5: Definite treatment need

Secondly, the Oral Health-Related Quality of Life was determined using a questionnaire. Students were explained for any questions, whenever required. The questionnaire was Oral Health Impact Profile (OHIP); which is composed of 49 questions associated with oral health. The participants were asked to point out on a five-point likert scale on how often each problem was experienced within a reference period of 12 months. Response categories for the five-point scale were: "very often", "fairly often", "occasionally", "hardly ever" and "never". For three questions that asked about denture-related problems; a response option was provided for non-wearers of dentures to indicate that these questions do not apply to them. The OHIP scores were then obtained.

The data were processed and analyzed using SPSS Version 17.0. Data entry for IOTN was done as per the DHC grades. The OHIP scores were entered as follows: responses were coded 0 for "never or not applicable", 1 for "hardly ever", 2 for "occasionally", 3 for "fairly often" and 4 for "very often". Blank entries were entered as missing values, which subsequently were recorded with the mean value of all valid responses to the corresponding question.

During data processing, coded responses for each question in the OHIP were multiplied by the corresponding weight for each question and the products summed within each dimension to give seven subscale scores, each with a potential range from zero (no impact) to 40 (all impacts reported "very often").

The results were then analyzed and correlated with those of the IOTN and final results were obtained and presented in tables and figures. The tests used during analysis were Chi-square test and ANOVA.

\section{RESULT}

In the study, majority of the study sample were female i.e.78\%; while $22 \%$ were males. Figure 1 shows the distribution of total study sample according to Index of Orthodontic Treatment Need - Dental Health Component. According to the study; most of the sample i.e. $40 \%$ showed 'borderline need for treatment', while $30 \%$ showed definite need, $22 \%$ little need, and $8 \%$ did not need treatment. 
Figure 2 shows the distribution of the study sample according to IOTN-DHC in relation to gender. Most of the male sample (54.5\%) had 'borderline need for treatment', $36.4 \%$ had 'definite need', and $9.1 \%$ had 'no need for treatment', while no males had 'little need for treatment'. Females however, were more evenly distributed; $28.2 \%$ had 'definite need for treatment', $35.9 \%$ had 'borderline need', 28.2\% 'little need', and 7.7\% 'no need'.

Table 1 shows Oral Health Impact Profile (OHIP) scores in relation to IOTN-DHC. Those with definite need for treatment showed higher impacts on oral health in relation to functional limitation and physical pain than those who had borderline need, little need, or no need for treatment. Nonetheless, this was not statistically significant.

Figure 3 shows OHIP scores in relation to gender in those who had 'no need for treatment' according to IOTN-DHC. Males having 'no need of treatment' scored higher in functional limitation than females, while females had a higher overall OHIP score. However, this is not statistically significant. Figure 4 shows
OHIP scores in relation to gender in those who had 'little need for treatment' according to IOTN-DHC. None of the males in the sample had 'little need for treatment'. The figure shows that females with 'little need for treatment' scored higher in physical pain than other domains. Figure 5 shows OHIP scores in relation to gender in those who had 'borderline need for treatment' according to IOTN-DHC. The figure shows that both genders with 'borderline need for treatment' scored higher in physical pain and psychological discomfort than other domains.

Males scored higher than females in psychological disability and handicap, while both genders had similar scores for social disability. Males also showed higher overall OHIP score than females. Nonetheless, this was not statistically significant.

Figure 6 shows that females with 'definite need for treatment' scored highest in physical pain than other domains, while males of the same treatment need scored highest in psychological discomfort than other domains. Males scored higher than females in functional limitation, physical disability, and handicap, as well as showing a higher overall OHIP score than females.

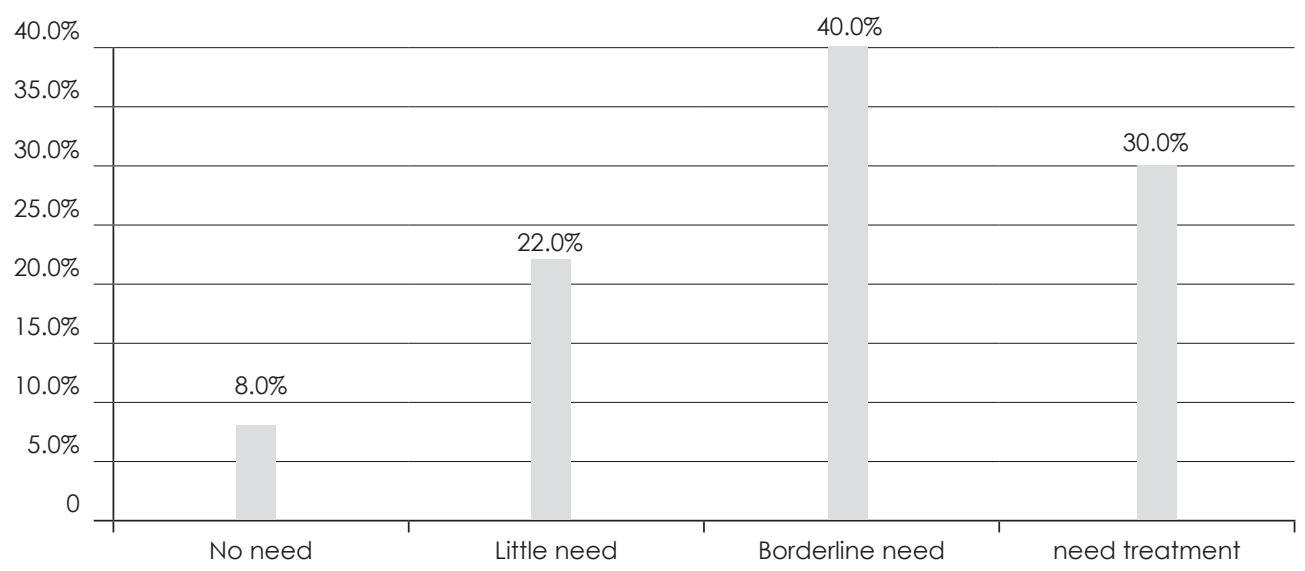

Figure 1: Distribution of total sample according to IOTN-DHC

Index of Orthodontic Treatment Needs (Dental Health Component)- IOTN (DHC)

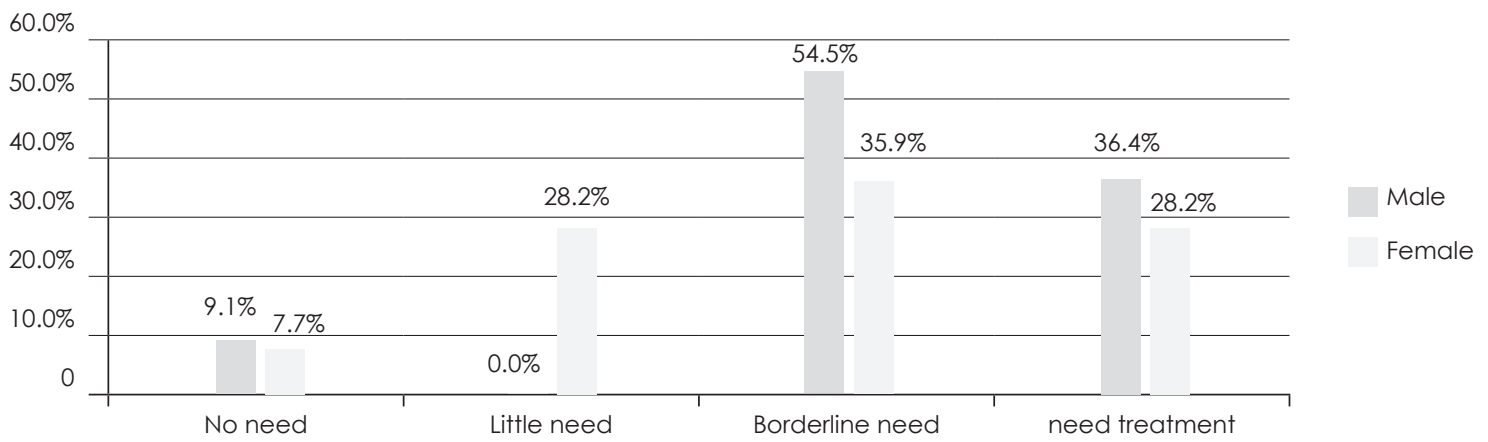

Figure 2: Distribution of the study sample according to IOTN-DHC in relation to gender 
Table 1: Oral Health Impact Profile scores in relation to IOTN-DHC

\begin{tabular}{|c|c|c|c|c|c|c|c|c|c|}
\hline & & $\begin{array}{l}\text { Functional } \\
\text { limitation }\end{array}$ & $\begin{array}{l}\text { Physical } \\
\text { pain }\end{array}$ & $\begin{array}{l}\text { Psycho- } \\
\text { logical } \\
\text { discomfort }\end{array}$ & $\begin{array}{l}\text { Physical } \\
\text { disability }\end{array}$ & $\begin{array}{l}\text { Psycho- } \\
\text { logical } \\
\text { disability }\end{array}$ & $\begin{array}{c}\text { Social } \\
\text { disability }\end{array}$ & Handicap & $\begin{array}{l}\text { Overall } \\
\text { OHIP } \\
\text { scores }\end{array}$ \\
\hline \multirow{5}{*}{ 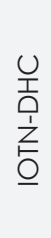 } & No need & $6.9 \pm 4.1$ & $4.8 \pm 5.5$ & $7.3 \pm 5.6$ & $2.2 \pm 0.9$ & $4.7 \pm 9.5$ & $2.2 \pm 4.5$ & $0.0 \pm 0.0$ & $28.2 \pm 22.7$ \\
\hline & Little need & $4.0 \pm 3.1$ & $9.7 \pm 5.7$ & $7.0 \pm 6.8$ & $3.1 \pm 2.3$ & $2.4 \pm 3.6$ & $0.7 \pm 2.5$ & $2.4 \pm 4.0$ & $29.3 \pm 21.1$ \\
\hline & Borderline need & $7.4 \pm 3.7$ & $8.9 \pm 6.2$ & $9.3 \pm 8.1$ & $4.8 \pm 4.4$ & $5.0 \pm 8.4$ & $3.6 \pm 5.9$ & $3.3 \pm 4.5$ & $41.3 \pm 28.8$ \\
\hline & Need treatment & $7.4 \pm 4.2$ & $11.6 \pm 5.8$ & $7.8 \pm 6.5$ & $3.6 \pm 4.3$ & $2.5 \pm 4.1$ & $1.6 \pm 2.7$ & $2.7 \pm 5.5$ & $37.0 \pm 24.7$ \\
\hline & $p$-Value & 0.097 & 0.213 & 0.828 & 0.459 & 0.606 & 0.311 & 0.612 & 0.580 \\
\hline
\end{tabular}

scores in Mean \pm S.D

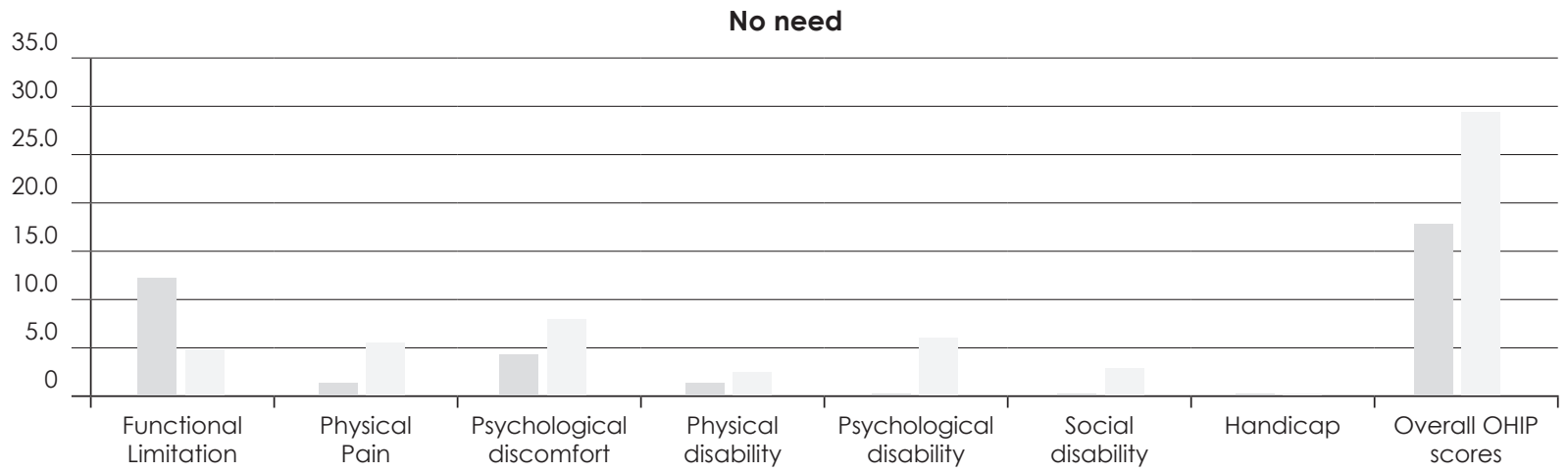

Figure 3: Mean OHIP scores in relation to gender in those who had 'no need

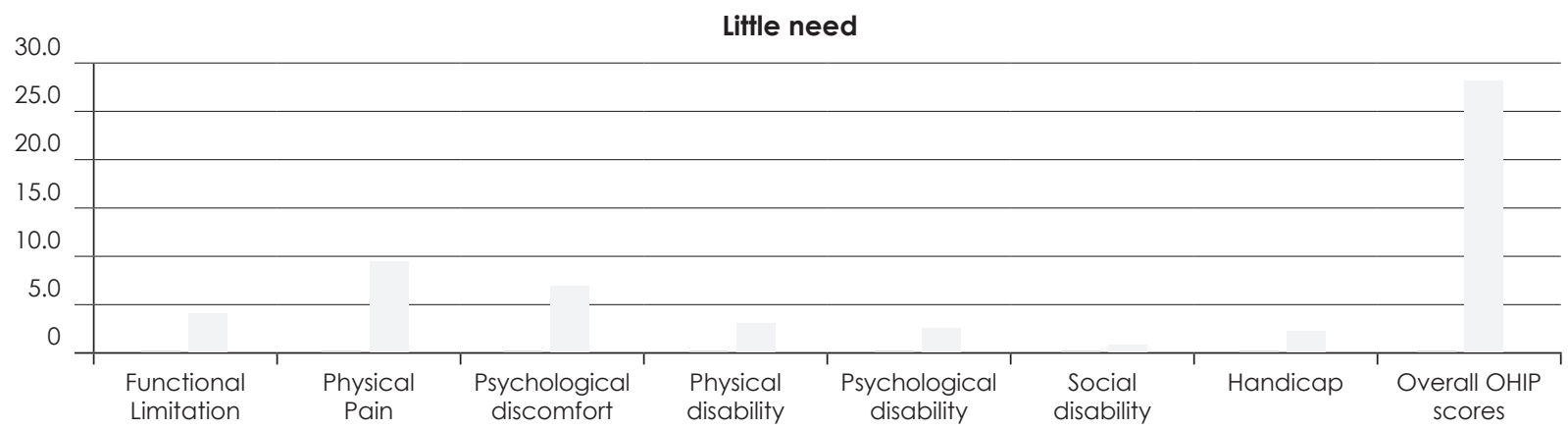

Figure 4: Mean OHIP scores in relation to gender in those who had 'little need for treatment' according to IOTN-DHC

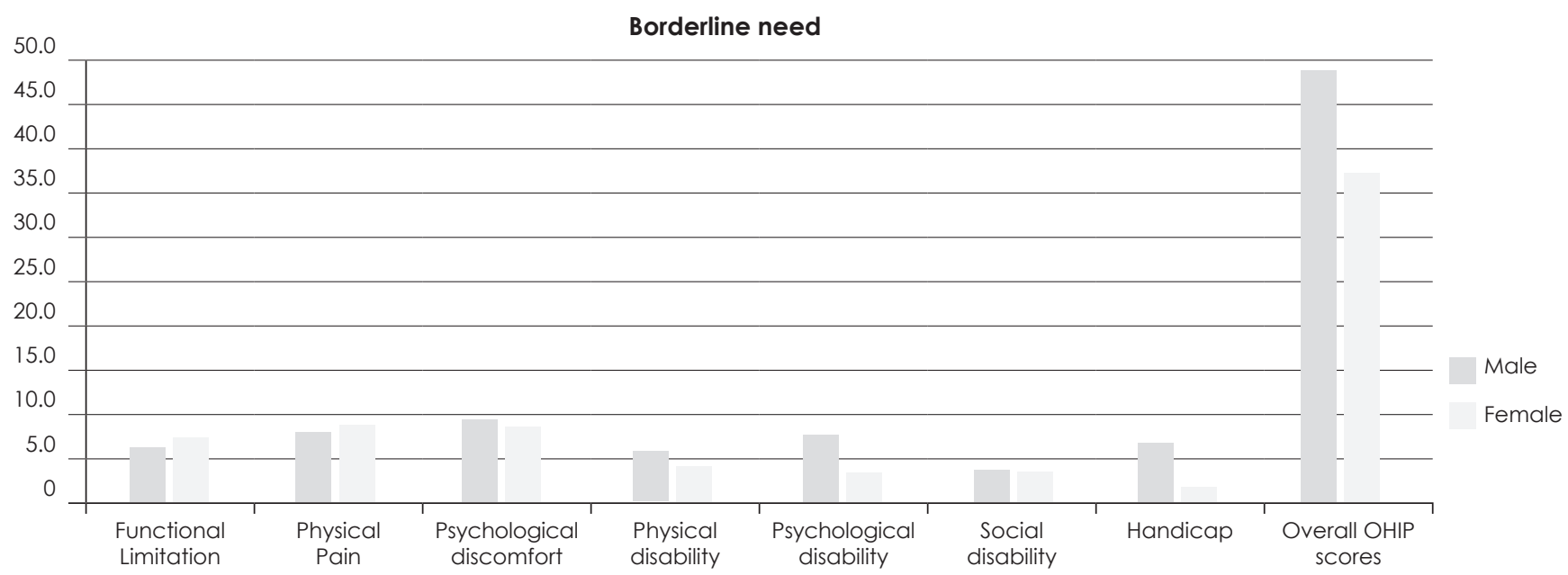

Figure 5: Mean OHIP scores in relation to gender in those who had 'borderline need for treatment' according to IOTN-DHC 


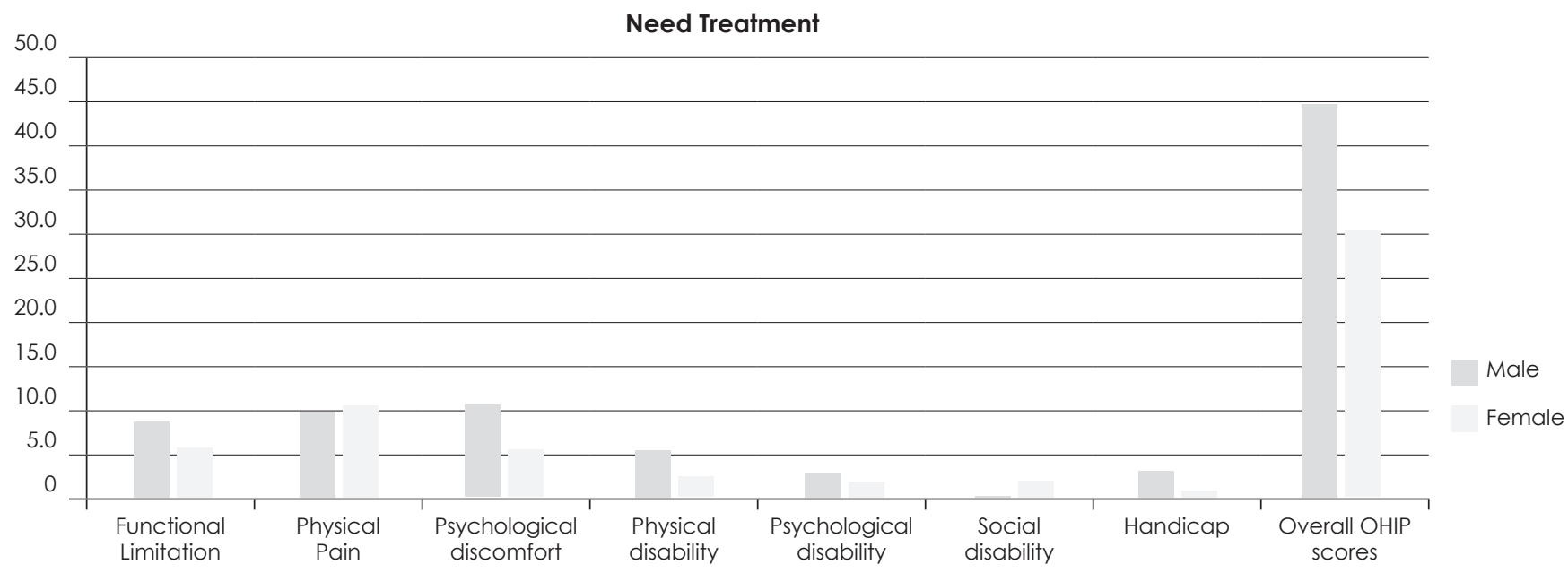

Figure 6: Mean OHIP scores in relation to gender in those who had 'definite need for treatment' according to IOTN-DHC

\section{DISCUSSION}

It has become widely accepted that assessment of the oral health-related quality of life plays an important role in clinical practice; $;, 5,7,17-20$ this is particularly true in the treatment of malocclusion.

The result of this study showed that the orthodontic treatment needs related to dental health did not significantly affect the oral health-related quality of life, which are consistent with the results of Vig et a ${ }^{21}$ and Taylor et al. ${ }^{5}$ Both studies were carried out on children/adolescent in the United States. The studies examined the effect of malocclusion and its treatment on the oral health-related quality of life.

However, the results of this study differed from other numerous studies; $2,5,14-16$ which found a significant negative effect of malocclusion on oral health-related quality of life.

Liva performed systematic review on the impact of malocclusion/orthodontic treatment needs on oral healthrelated quality of life. ${ }^{3}$ Hassan and Amin assessed the effect of different orthodontic treatment need on oral health-related quality of life in Saudi Arabian young adult orthodontic patients. ${ }^{6}$ Klages et al examined the relationship between dental esthetics and oral health-related quality of life in a group of German university students. ${ }^{15}$

When comparing OHIP scores of the present study in relation to gender in those who had 'definite need for treatment' according to the IOTN-DHC, it was found that females with 'definite need for treatment' scored highest in physical pain than other domains, while males of the same treatment need scored highest in psychological discomfort. This result is again in contrast to other studies conducted on similar subject. 5.14

An interesting feature of the results of this study was that, although the responses indicated no association between orthodontic treatment need and oral health-related quality of life, it is clear that the standard deviations were large when the OHIP was assessed with IOTN-DHC, as well as gender. This may indicate that the malocclusion status alone did not determine oral health-related quality of life and other factors possibly contributed to the impacts on oral health. Other study such as $\mathrm{Page}^{16}$ controlled confounding factors where the caries index was accounted for using the DMFT score. Some studies focused only on aesthetics including Klages et $a^{15}$ and Page et al. ${ }^{16}$ Malocclusion is much as an anatomical phenomenon as it is a social one, therefore leaving out one or the other does not give the true essence of the impact.

This study is the first in Sudan to use both Oral Health Impact Profile (OHIP), and Index of Orthodontic Treatment Needs (Dental Health Component) to investigate the effect of malocclusion on oral health-related quality of life of dental students. This method was used as it has been used in many other studies. $2,5,13,14$

However, some limitations do occur as the sample size was small. The study might have shown a clear association if the variety of malocclusions in the general population were represented. Therefore, a larger sample is required to support this research. The subjects in the present study were dental students who have better access to dental care and more knowledge in the field of dentistry. Thus the result cannot be generalized to the population of young Sudanese adults requiring orthodontic treatment.

\section{CONCLUSION}

Orthodontic treatment need as related to dental health per se does not impact the oral health-related quality of life, but it plays a vital role. Males with 'definite' and 'borderline need for treatment' generally showed significantly higher OHIP scores in the handicap domain than the females. Females, on the other hand, with 'no need for treatment' had more impacts on overall oral health than males of the same category. 


\section{REFERENCES}

1. Cunningham SJ, O'Brien C. Quality of life and orthodontics. Semin Orthod 2007; 13(2):96-103.

2. Hans MG, Valiathan M. Bobbing for apples in the garden of Eden. Semin Orthod 2005; 11:86-93.

3. Liva Z, McGrathb C, Ha"ggc U. The impact of malocclusion/ orthodontic treatment need on the quality of life: A systematic review. Angle Orthod 2009; 79:585-91.

4. Hassan AH. Orthodontic treatment needs in the western region of Saudi Arabia: A research report. Head \& Face Medicine 2006; 2:2

5. Taylor KR, Kiyak A, Huang GJ, Greenlee GM, Jolley CJ, King GJ. Effects of malocclusion and its treatment on the quality of life of adolescents. Am J Orthod Dentofacial Orthop 2009; 136:382-92.

6. Hassan AH, Amin HE. Association of orthodontic treatment needs and oral health-related quality of life in young adults. Am J Orthod Dentofacial 2010; 137:42-7.

7. Bedi R, Gulati N, McGrath C. A study of satisfaction with dental services among adults in the United Kingdom. Br Dent J 2005; 198:433-7.

8. MCGrath C, Bedi R. The value and use of "quality of life" measures in the primary dental care setting. Prim Dent Care 1999; 6: 53-7.

9. Palomares NB, Celeste RK, deOliveira BH, Migueld JAM.. How does orthodontic treatment affect young adults' oral health-related quality of life? Am J Orthod Dentofacial Orthop 2012; 141(6):751-8.

10. Marques LS, Ramos-Jorge ML, Paiva SM, Pordeus IA. Malocclusion: Esthetic impact and quality of life among Brazilian schoolchildren. Am J Orthod Dentofacial Orthop 2006; 129:424-7

11. Brook PH, Shaw WC: The development of an index of orthodontic treatment priority. Eur J Orthod 1989, 11:309-320.

12. Anneli M. Johansson, Marie E. Follin. Evaluation of the Dental Health Component of the Index of Orthodontic Treatment Need by Swedish orthodontists. Eur J Orthod 2009; 31:184-8.

13. Slade GD, Spencer AJ. Development and evaluation of the Oral Health Impact Profile. Community Dent Health.

14. de Oliveira CM, Sheiham A. Orthodontic treatment and its impact on oral health-related quality of life in Brazilian adolescents. J Orthod 2004; 31:20-7.

15. Klages U, Bruckner A, Zentner A. Dental aesthetics, self-awareness, and oral health-related quality of life in young adults. Eur J Orthod 2004; 26:507-14.

16. Page LAF, Thomson WM, Jokovic A, Locker D. Validation of the Child Perceptions Questionnaire (CPQ1 1-14). J Dent Res 2005; 84(7):649652.

17. Spalj S, Slaj M, Varga S, Strujic M, Slaj M. Perception of orthodontic treatment need in children and adolescents. Euro J Orthods 2010; 32:387-394

18. Shivakumar KM, Chandu GN, Subbareddy VV, Shafiulla MD. Prevalence of malocclusion and orthodontic treatment needs among middle and high school children of Davangere city, India by using Dental Aesthetic Index. J Indian Soc Pedod Prevent Dent 2009; 4:21 1-8.

19. Shivakumara KM, Chandub GN, Shafiullac MD. Severity of malocclusion and orthodontic treatment needs among 12-15 year-old school children of Davangere district, Karnataka, India. Eur J Dent 2010; 4:298-307.

20. Gary D. Slade Measuring Oral Health and Quality of Life. North Carolina: Department of Dental Ecology; 1997.

21. Vig KWL, Firestone A, Wood W, Lenk M. Quality of Orthodontic Treatment. Semin Orthod 2007; 13:81-87. 